\section{Women winners of Nobel Prize}

SIR-In my review of Grand Obsession: Marie Curie and Her World (Nature 343, $707 ; 1990)$, I said that Marie Curie was the only woman to have won the Nobel prize for physics. I should have known better, and now I do - thanks to all those who have written to me. Maria GoeppertMayer won the prize in 1963 for the shell theory of the atomic nucleus.

JOHN GALLOWAY

\section{Cancer Research Campaign \\ 2 Carlton House Terrace, \\ London SW1Y 5AR, UK}

SIR - John Galloway's book review needs some correction.

(1) Marie Curie is not "the only woman ever to have won the prize for physics". Maria Goeppert Mayer won the 1963 Nobel physics prize.

(2) "No woman other than a Curie had won the prize for science until Dorothy Hodgkin in 1964" is also erroneous. Apart from Mayer, Gerty Cori won the Nobel prize for medicine in 1947 with her husband Carl Cori.

(3) So far, there have been 21 women Nobel prizewinners:

Chemistry - Marie Curie, Irene Joliot Curie and Dorothy Hodgkin; Physics Marie Curie and Maria Goeppert-Mayer; Medicine - Gerty Cori, Rosalyn Yallow, Barbara McClintock, Rita Levi Montalcini and Gertrude Elion; Literature Grazia Deledda, Sigrid Undset, Pearl Buck, Gabriela Mistral and Nelly Sachs; Peace - Bertha von Suttner, Jane Addams, Emily Balch, Mairead Corrigan, Elizabeth Williams, Mother Teresa and Alva Mydral.

Department of Physiology and Biochemistry,

Medical College of Pennsylvania, Philadelphia, Pennsylvania 19129, USA

\section{Material increases}

SIR-Under the heading "Hidden increases", Ian Winship (Nature 342, 730; 1989) complained about publishers adding new sections to an established periodical and the consequent increase in price. In the case of Journal of Materials Science, which he mentions, there was nothing hidden; information about the changes was circulated at the usual time in the preceding autumn.

Our reason for adding the new sections was that research in materials science is burgeoning, and that the increasing number of good papers being submitted for publication would soon have led to a serious backlog. We did not want to split the journal because its point is that it covers the whole field. And it would in any case have been difficult to transfer papers destined for publication in the journal to new, more specialized ones, because of the problem of building up subscriptions from scratch: our evidence was that contributors would simply refuse.

That is why we started two quarterly adjunct journals in key growth areas (materials in medicine and materials in electronics), both of which are part of the main subscription and available separately for those with specialist interests. That had to be reflected in an increased subscription rate, although we did not in practice pass on all the extra costs to subscribers.

Like other librarians faced with the need to manage budgets that are declining in real terms, Winship blames publishers for increasing the size and price of journals. He forgets that, to survive, publishers have to be responsive to the needs of the scientific community, which in some subjects means providing supplementary journals for the increasing number of good papers that are offered.

\section{Chapman \& Hall,}

11 New Fetter Lane,

London EC4P 4EE, UK

\section{Random chaos}

SIR-Thomas Ochs' asks too much when he requires authors to be as stringent in the use of 'random' as in the use of 'chaotic'. It is impossible to prove that something is truly random. For any system, it is always possible that a discovery will lead to predictability, even if this is only partial. For many systems, that of tossing an unbiased coin being one, it is only the limits of observation that prevent prediction. The only logical conclusion of Ochs's argument is that random must, in all its uses, be preceded by 'apparently' or prefixed by 'pseudo-'.

What puzzles me is why the word 'chaos' was chosen. The dictionary meaning is "utter confusion', which dynamic chaos plainly is not. Explaining chaos to those who know nothing about it is not made easier by such a commonplace word. At the least, spelling it 'kaos' would have helped but even better would have been a word from a nonsense poem, or something similar. The physicists found 'quark' when naming subatomic particles; it is too late now, but 'caucus' might have done instead of 'chaos', from Lewis Carroll's caucus-race. This required a racecourse in a sort of circle whose exact shape did not matter; the competitors were placed "along the course, here and there";

Letters submitted for Correspondence should be typed, double-spaced, on one side of the paper only. and there was no start or finish, so it was not easy to tell when the race was over. The connection between caucus, politics ${ }^{3}$ and what we now term chaotic behaviour would have added piquancy.

NEVILLE W. GoOdMAN

University of Bristol,

Department of Anaesthetics,

Southmead Hospital,

Southmead Road, Bristol BS10 5NB, UK

1. Ochs, T.L. Nature 343, 303 (1990).

2. Concise Oxford Dictionary, 7 th Edn (1982)

3. Gardner, M. (Ed.) The Annotated Lewis Carroll (Harmondsworth, Penguin, 1970).

\section{Problems}

SIR - I am less inclined than is J.Z. Young to be grateful for the latest lucubrations of Sir John Eccles, or to feel that they deal with "serious and difficult problems of science and philosophy" ("A change of mind", review of Evolution of the Brain: Creation of the Self, Nature 344, 117; 1990).

They deal with Eccles's religious inclinations, for example: "... I am constrained to attribute the uniqueness of the Self or Soul to a supernatural spiritual creation ... . each Soul is a new Divine creation which is implanted into the growing fetus at some time between conception and birth". Parliament, now exercising itself over a similar conundrum, would doubtless be interested to know exactly when this miracle occurs. At 14 weeks? 18 weeks? 22, 24, less than 14, more than 24 ? Can Eccles be a little more specific?

And does he believe, as Young indicates he does, that all mammals and birds have 'souls'? But not reptiles, amphibia, fish, bees and cephalopods?

Young asks at what stage of human evolution did hominids first receive their souls. The matter is in fact covered by the 1950 papal encylical Humani Generis, which explains that the soul was acquired during the early Pleistocene, 800,000 years ago, apparently in Kenya.

While Eccles's meditations on these "serious and difficult problems", at $£ 30$ a meditation, are no doubt of interest to Eccles, they are of no concern to anyone else.

I have, as you may recall, brought matters of this kind to your urgent attention on two previous occasions (Nature 323, 754; 1986 and 338, 536; 1989). Questions of one's religious convictions do not concern Me but their espousal within these pages does, this because, although certainly not a jealous God, I am a seriousminded One. Accordingly, I do not feel they form a necessary adjunct to scientific methods or attitudes.

(As revealed to Ralph Estling)

The Old Parsonage,

Dowlish Lake,

IIminster, Somerset TA19 ONY

NATURE · VOL $344 \cdot 12$ APRIL 1990 